\title{
Effects of postpartum mobile phone-based education on maternal and infant health in Ecuador
}

\author{
Julie Maslowsky $^{\mathrm{a}, *}$, Sara Frost $^{\mathrm{b}}$, C. Emily Hendrick ${ }^{\mathrm{a}}$, Freddy O. Trujillo Cruz $^{\mathrm{c}}$, Sofia D. Merajver ${ }^{\mathrm{d}}$ \\ a Department of Kinesiology and Health Education and Population Research Center, University of Texas, Austin, TX, USA \\ b Department of Obstetrics and Gynecology, University of Michigan, Ann Arbor, MI, USA \\ c Department of Epidemiology, Universidad Técnica Equinoccial and Hospital General Enrique Garcés, Quito, Ecuador \\ d Departments of Internal Medicine and Epidemiology, University of Michigan, Ann Arbor, MI, USA
}

\section{A R T I C L E I N F O}

\section{Article history:}

Received 10 July 2015

Received in revised form 29 November 2015

Accepted 23 March 2016

\section{Keywords:}

Breastfeeding

Newborn health

Maternal health

Mobile phone

\begin{abstract}
A B S T R A C T
Objective: To evaluate the effects of a mobile phone-based intervention on postnatal maternal health behavior and maternal and infant health in a middle-income country. Methods: A prospective evaluation enrolled consecutive postpartum women at two public hospitals in Quito, Ecuador, between June and August 2012. Inclusion criteria were live birth, no neonatal intensive care admission, and Spanish speaking. Intervention and control groups were assigned via random number generation. The intervention included a telephone-delivered educational session and phone/text access to a nurse for 30 days after delivery. Maternal and infant health indicators were recorded at delivery and 3 months after delivery via chart review and written/telephoneadministered survey. Results: Overall, 102 women were assigned to the intervention group and 76 to the control group. At 3 months, intervention participants were more likely to attend the infant's postnatal check-up $(P=0.022)$ and to breastfeed exclusively $(P=0.005)$, and less likely to feed formula $(P=0.016)$. They used more effective forms of contraception (more implants $P=0.023$; fewer condoms $P=0.036$ ) and reported fewer infant illnesses $(P=0.010)$. There were no differences in maternal acute illness or check-up attendance. Conclusion: Mobile phone-based postnatal patient education is a promising strategy for improving breastfeeding, contraceptive use, and infant health in low-resource settings; different strategies are needed to influence postpartum maternal health behavior.

(C) 2016 International Federation of Gynecology and Obstetrics. Published by Elsevier Ireland Ltd. All rights reserved.
\end{abstract}

\section{Introduction}

Despite significant improvements in recent decades, maternal and infant health outcomes in low- and middle-income countries fall short of 2015 Millennium Development Goals and lag behind those of highincome nations [1,2]. Much of the maternal and infant morbidity and mortality in these countries is amenable to intervention during the postpartum period [3]. However, the barriers of overburdened healthcare systems limit access to care [4]. Malnutrition, diarrhea, respiratory infections, and death are common among infants in low- and middle-income countries such as Ecuador [4], in part likely due to low levels of exclusive breastfeeding and attendance at preventive postpartum care.

Despite advances in health service utilization and infant survival since the Law for the Provision of Free Maternity and Child Care in Ecuador was passed in 2002 [5], less than 50\% of new mothers in Ecuador attend a postpartum visit [4]. Consequently, this early opportunity to identify and address complications, as well as educate mothers

\footnotetext{
* Corresponding author at: University of Texas at Austin, 2109 San Jacinto D3700, Bellmont 508, Austin, TX 78712-0360, USA. Tel.: + 1512471 7190; fax: + 15124713845.

E-mail address: maslowsky@austin.utexas.edu (J. Maslowsky).
}

on breastfeeding, infant vaccination, and birth spacing, is being missed. Increasing access to preventive postpartum care has the potential not only to improve maternal and infant health outcomes, but also to reduce the use of emergency rooms and health centers for preventable conditions among this population [6]. Ecuador's recent National Plan to Reduce Maternal and Infant Mortality [7] includes postpartum patient education as one of its five strategies.

The near ubiquity of mobile phones means that this technology is an emerging vehicle for low-cost innovation in postpartum care [8,9]. The widespread use of mobile phones has led to a proliferation of mobile phone-based health promotion programs, many specifically targeting maternal and infant health [10-12]. Mobile phone interventions have been tested to address postpartum depression [13], breastfeeding practices [14,15], and perinatal mortality [16] with promising results, although widespread implementation is still in development. However, most of this evidence is based on research conducted in high-resource countries, whereas the potential of mobile phones to significantly improve maternal and infant health in lower-income countries has not been fully tested or realized [10,17].

Some mobile phone-based interventions in Latin America have shown promise. In Ecuador, for example, using mobile phones to provide post-hospitalization follow-up care was found to be feasible 
and acceptable among patients recently discharged from hospitals, most of whom were new mothers [18]. Overall, 97\% of participants made mobile phone contact with a community-based nurse within 1 month of hospital discharge, consequently linking $87 \%$ of participants to follow-up appointments-a vast improvement over the estimated national averages of less than $50 \%[4,19]$.

Ecuador is a middle-income country with a gross national income per capita of US\$5760 in 2013 [19]; southern Quito is a peri-urban low-income area. Mobile phone penetration in Ecuador is more than $100 \%$, with 103 active mobile phone subscriptions per 100 inhabitants [20]. The aim of the present study was therefore to evaluate the effects of a mobile phone-based intervention, providing postpartum health education and support plus 30 days of telephone access to a dedicated on-call nurse, on postnatal maternal health behavior and maternal and infant health in Ecuador. It was considered that this intervention might fill the gap in continuity of care, and supplement family and community support for a vulnerable, low-resource population.

\section{Materials and methods}

The present prospective evaluation enrolled consecutive inpatient mothers after delivery of their newborn at a large public hospital or a community clinic with a birthing center in southern Quito, Ecuador, between June 1 and August 31, 2012. Mothers were eligible for the study if they were at least 15 years old and spoke Spanish, and their newborn had not been admitted to the neonatal intensive care unit. Participants were compensated with $\$ 5$ mobile phone credit for completing each of the two surveys, one at baseline and one at the 3-month follow-up. Study procedures were approved by the University of Michigan Institutional Review Board and the Universidad San Francisco de Quito Committee of Bioethics. Written informed consent was obtained from all participants.

At enrollment, participants were assigned via a random number generator to either the intervention or the control group. Because the intervention and follow-up data collection were conducted via telephone, it was essential to maximize the ability to make contact with participants. Each participant completed a "communication plan" worksheet at enrollment, in which she provided all of the following information as applicable: home phone number, her own mobile phone number, her email address, mobile phone number(s) of her partner or other members of her household, and name and phone number of someone who would always know how to contact her. All participants provided at least one phone number. Each participant also indicated the days of the week and times of day that were best to reach her.

Mothers assigned to the control group received treatment as usual, consisting of brief discharge instructions delivered by a nurse at the time of hospital or clinic discharge. These instructions typically include a newborn check-up within 1 week, a maternal follow-up visit within 6 weeks, and initiation of a family planning regimen. In standard practice, if mothers require additional support during the postnatal period, they are instructed to attend a local health center or emergency room.

Mothers assigned to the intervention group received a two-part intervention in addition to the standard treatment. Both parts of the intervention were delivered by one bachelor-degree-level, licensed Ecuadorian nurse with more than 15 years of clinical experience. Part 1 consisted of an educational session administered by the nurse via phone within $48 \mathrm{~h}$ of hospital discharge. The nurse followed a semi-structured patient education protocol, guided by a checklist of topics to cover and bullet points detailing the information to be provided, to ensure that all participants received the same information (Table 1). This information was developed by the study team in conjunction with local physicians and nurses using best practices information disseminated by the Ecuadorian Ministry of Health. Participants were encouraged to ask questions as needed during the education session.

Part 2 of the intervention consisted of access to a nurse on-call during the first 30 days of the newborn's life. Patients were instructed that they could call the nurse during their 30-day follow-up period to ask questions regarding their own or their newborn's health and care, as needed. The nurse provided medical advice, information, and support, and triaged patients to determine whether a clinic visit was needed to address each complaint. The nurse was available via phone from 8 am to $5 \mathrm{pm}$, Monday to Friday. Patients were cautioned that the nurse on-call service was not intended for use in emergency situations. In case of emergency, they were instructed to call the hospital or health center emergency phone numbers, or to go to the emergency room as per the usual process.

All participants completed baseline survey questions at the time of enrollment. Clinical characteristics consisting of maternal obstetric history and prenatal care, and the gestational age, birth weight, length, and Apgar scores of the newborn were assessed by means of in-patient chart review. Demographic characteristics consisting of age, race or ethnicity, marital status, education, and employment were self-reported by the mother at enrollment. All additional measures were self-reported by the mother at the follow-up interview, which was conducted via telephone 3 months after initial enrollment in the study.

Breastfeeding and formula use were assessed by mothers' reports of whether they were exclusively breastfeeding (yes/no) and whether they were currently feeding the infant any formula (yes/no). Infant check-up attendance was assessed by mothers' reports of whether their infant attended well-baby check-ups at 1 week and 2 months of age (yes/no). Mother check-up attendance was assessed by mothers' reports of whether they attended the maternal postpartum check-up (yes/no). Contraception use was assessed by mothers' reports of whether they were using contraception (yes/no) and the type of contraception that they were using. Acute episodes of illness in infants were assessed

Table 1

Content of postpartum education session.

\begin{tabular}{|c|c|}
\hline Topic & Discussion points \\
\hline \multicolumn{2}{|l|}{ Newborn } \\
\hline Feeding & $\begin{array}{l}\text { Breastmilk (preferably) or formula only; frequency of feeding; wake to feed; burp after each feed; no juice, water, honey, or solids; } \\
\text { breastfeeding techniques; monitor output }\end{array}$ \\
\hline Safe sleeping & Sleep on back; swaddle tightly; no loose blankets or stuffed animals; avoid co-sleeping if possible \\
\hline Environment & No smoke; quiet environment; supervise other children with newborn \\
\hline Health red flags & Fever $>38^{\circ} \mathrm{C}$; fast breathing; difficult to arouse; no wet diapers \\
\hline Recommended appointments & 1-week post partum; vaccine schedule; weight check; registering the birth \\
\hline Excessive crying & Check for red flags; change diaper; swaddle; burp; help mother identify sources of support \\
\hline \multicolumn{2}{|l|}{ Mother } \\
\hline Recognizing/preventing infection & Fever; pain with urination; bleeding/red/painful breasts; proper wound and breast care \\
\hline Bleeding & Bleeding for 2-6 weeks is normal; it decreases with time; seek medical attention for heavy bleeding ( $>1 \mathrm{pad} / \mathrm{h}$ ) or fainting \\
\hline Pain & Ibuprofen or acetaminophen; seek medical attention if not well controlled \\
\hline Voiding & Avoiding constipation; hemorrhoid care; seek medical attention if painful voiding or new incontinence \\
\hline Contraception & No intercourse for 6 weeks; review types and effectiveness of contraception \\
\hline Mood & Postpartum depression is common; signs of postpartum depression; seek medical attention if experience depression, anxiety, suicidality \\
\hline
\end{tabular}




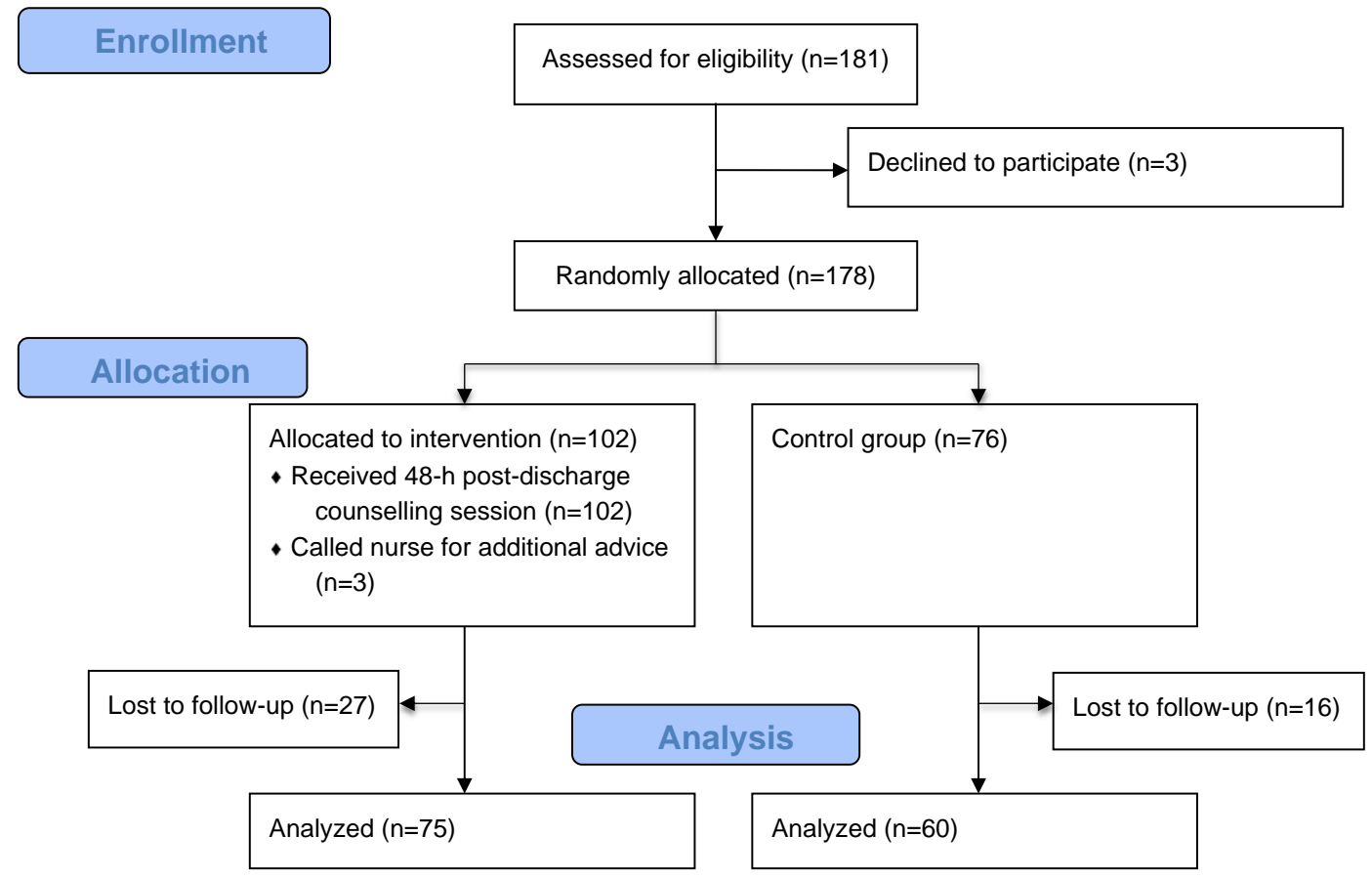

Fig. 1. Recruitment and retention of study participants and analysis of data.

via mothers' reports of how many times since birth, on a six-point scale ( 0 to $\geq 5$ episodes), the infant had experienced an acute health problem requiring a clinic visit.

The topics of primary concern in the nurse-patient phone calls were recorded by a research team member, who monitored each 48-h postpartum phone education session and, in conjunction with the nurse who conducted the call, recorded each topic on which a mother asked for additional information, indicating the particular salience of that topic. Program satisfaction was assessed via three items, each with a three-point response scale (disagree, neither agree nor disagree, or agree).
Data were analyzed using SPSS version 21 (IBM, Armonk, NY, USA). Differences between the intervention and control groups at the 3-month follow-up were assessed by using independent sample $t$ tests and $\chi^{2}$ tests. $P<0.05$ was considered statistically significant.

\section{Results}

During the study period, 178 new mothers were enrolled and randomly assigned to either the intervention $(n=102)$ or control $(n=76)$ group (Fig. 1$)$. Retention was robust: $73.5 \%(n=75)$ of the intervention group and $78.9 \%(n=60)$ of the control group attended

Table 2

Demographic characteristics of the study participants. ${ }^{\text {a }}$

\begin{tabular}{|c|c|c|c|c|c|}
\hline Characteristic & $\begin{array}{l}\text { Total } \\
(\mathrm{n}=178)\end{array}$ & $\begin{array}{l}\text { Intervention } \\
(\mathrm{n}=102)\end{array}$ & $\begin{array}{l}\text { Control } \\
(n=76)\end{array}$ & Statistic & $\begin{array}{l}P \\
\text { value }\end{array}$ \\
\hline Marital status & & & & $1.88^{\mathrm{b}}$ & 0.391 \\
\hline Single & $27(15.2)$ & $13(12.7)$ & $14(18.4)$ & & \\
\hline Married & $70(39.3)$ & $39(38.2)$ & $31(40.8)$ & & \\
\hline Unmarried committed relationship & $80(44.9)$ & $50(49.0)$ & $30(39.5)$ & & \\
\hline Missing & $1(0.6)$ & 0 & $1(1.3)$ & & \\
\hline Ethnic origin & & & & $3.24^{\mathrm{b}}$ & 0.357 \\
\hline Mestiza & $151(84.8)$ & $90(88.2)$ & $61(80.3)$ & & \\
\hline Indigenous & $16(9.0)$ & $7(6.9)$ & $9(11.8)$ & & \\
\hline White & $7(3.9)$ & $4(3.9)$ & $3(3.9)$ & & \\
\hline Afro-Ecuadorian & $4(2.2)$ & $1(1.0)$ & $3(3.9)$ & & \\
\hline Employed outside the home & & & & $0.01^{\mathrm{b}}$ & 0.531 \\
\hline Yes & $65(36.5)$ & $37(36.3)$ & $28(36.8)$ & & \\
\hline No & $113(63.5)$ & $65(63.7)$ & $48(63.2)$ & & \\
\hline Highest level of education & & & & $2.69^{\mathrm{b}}$ & 0.748 \\
\hline None & $8(4.5)$ & $3(2.9)$ & $5(6.6)$ & & \\
\hline Primary & $40(22.5)$ & $22(21.6)$ & $18(23.7)$ & & \\
\hline Some secondary & $44(24.7)$ & $26(25.5)$ & $18(23.7)$ & & \\
\hline Graduated from secondary & $55(30.9)$ & $34(33.3)$ & $21(27.6)$ & & \\
\hline Some education beyond secondary & $22(12.4)$ & $11(10.8)$ & $11(14.5)$ & & \\
\hline Graduated from university & $9(5.1)$ & $6(5.9)$ & $3(3.9)$ & & \\
\hline Age, y & $26.4 \pm 5.8$ & $27.0 \pm 5.4$ & $25.5 \pm 6.2$ & $1.76^{\mathrm{c}}$ & 0.080 \\
\hline Children in home (in addition to newborn) & $2.3 \pm 1.2$ & $2.3 \pm 1.2$ & $2.2 \pm 1.2$ & $0.80^{\mathrm{c}}$ & 0.424 \\
\hline
\end{tabular}

${ }^{\text {a }}$ Values are given as number (percentage) or mean $\pm \mathrm{SD}$, unless indicated otherwise.

b $\chi^{2}$ test statistic.

c $t$ test statistic. 
Table 3

Obstetric history of the study participants. ${ }^{\text {a }}$

\begin{tabular}{|c|c|c|c|c|c|}
\hline Characteristic & $\begin{array}{l}\text { Total } \\
(\mathrm{n}=178)\end{array}$ & $\begin{array}{l}\text { Intervention } \\
(\mathrm{n}=102)\end{array}$ & $\begin{array}{l}\text { Control } \\
(n=76)\end{array}$ & Statistic & $P$ value \\
\hline \multicolumn{4}{|l|}{ Mode of delivery } & $0.29^{\mathrm{b}}$ & 0.591 \\
\hline Vaginal & $137(77.0)$ & $80(78.4)$ & $57(75.0)$ & & \\
\hline Cesarean & $41(23.0)$ & $22(21.6)$ & $19(25.0)$ & & \\
\hline \multicolumn{6}{|c|}{ Trimester began prenatal care } \\
\hline None & $1(0.6)$ & 0 & $1(1.3)$ & $4.90^{\mathrm{b}}$ & 0.298 \\
\hline First & $121(68.8)$ & $67(65.7)$ & $54(71.1)$ & & \\
\hline Second & $43(24.4)$ & $29(28.4)$ & $14(18.4)$ & & \\
\hline Third & $10(5.6)$ & $5(4.9)$ & $5(6.6)$ & & \\
\hline Missing & $3(1.7)$ & $1(1.0)$ & $2(2.6)$ & & \\
\hline \multicolumn{6}{|c|}{ No. of prior pregnancies } \\
\hline 1 & $43(24.2)$ & $25(24.5)$ & $18(23.7)$ & $7.19^{\mathrm{b}}$ & 0.303 \\
\hline 2 & $54(30.3)$ & $27(26.5)$ & $27(35.5)$ & & \\
\hline 3 & $44(24.7)$ & $31(30.4)$ & $13(17.1)$ & & \\
\hline$\geq 4$ & $37(20.8)$ & $19(18.6)$ & $18(23.7)$ & & \\
\hline \multicolumn{6}{|c|}{ No. of full-term births } \\
\hline 0 & $2(1.1)$ & $2(2.0)$ & 0 & $5.77^{\mathrm{b}}$ & 0.567 \\
\hline 1 & $54(30.3)$ & $28(27.5)$ & $26(34.2)$ & & \\
\hline 2 & $55(30.9)$ & $33(32.4)$ & $22(28.9)$ & & \\
\hline 3 & $39(21.9)$ & $20(19.6)$ & $19(25.0)$ & & \\
\hline$\geq 4$ & $27(15.2)$ & $18(17.6)$ & $9(11.8)$ & & \\
\hline Missing & $1(0.6)$ & $1(1.0)$ & 0 & & \\
\hline \multicolumn{6}{|c|}{ No. of premature births } \\
\hline 0 & $164(92.1)$ & $92(90.2)$ & $72(94.7)$ & $0.74^{\mathrm{b}}$ & 0.389 \\
\hline 1 & $10(5.6)$ & $7(6.9)$ & $3(3.9)$ & & \\
\hline Missing data & $4(2.2)$ & $3(2.9)$ & $1(1.3)$ & & \\
\hline \multicolumn{6}{|c|}{ No. of induced abortions } \\
\hline 0 & $173(97.2)$ & $99(97.1)$ & $74(97.4)$ & $1.86^{\mathrm{b}}$ & 0.396 \\
\hline 1 & $4(2.2)$ & $3(2.9)$ & $1(1.3)$ & & \\
\hline 2 & $1(0.6)$ & 0 & $1(1.3)$ & & \\
\hline \multicolumn{6}{|c|}{ No. of spontaneous abortions } \\
\hline 0 & $144(80.9)$ & $85(83.3)$ & $59(77.6)$ & $1.97^{\mathrm{b}}$ & 0.578 \\
\hline 1 & $31(17.4)$ & $16(15.7)$ & $15(19.7)$ & & \\
\hline 2 & $2(1.1)$ & $1(1.0)$ & $1(1.3)$ & & \\
\hline 3 & $1(0.6)$ & 0 & $1(1.3)$ & & \\
\hline \multicolumn{6}{|l|}{ Apgar score } \\
\hline First & $19.4 \pm 105.0$ & $17.9 \pm 98.1$ & $21.5 \pm 114.4$ & $-0.22^{\mathrm{c}}$ & 0.824 \\
\hline Second & $20.1 \pm 104.9$ & $18.6 \pm 98.0$ & $22.1 \pm 114.3$ & $-0.22^{\mathrm{c}}$ & 0.826 \\
\hline Birth weight, g & $3068.3 \pm 406.2$ & $3070.7 \pm 424.3$ & $3065.1 \pm 383.2$ & $0.09^{c}$ & 0.928 \\
\hline Length at birth, $\mathrm{cm}$ & $47.8 \pm 2.3$ & $47.9 \pm 2.5$ & $47.6 \pm 2.1$ & $0.91^{\mathrm{c}}$ & 0.360 \\
\hline $\begin{array}{l}\text { Gestational age at } \\
\text { delivery, wk. }\end{array}$ & $39.2 \pm 1.3$ & $39.2 \pm 1.4$ & $39.3 \pm 1.0$ & $-0.26^{c}$ & 0.793 \\
\hline
\end{tabular}

a Values are given as number (percentage) or mean \pm SD, unless indicated otherwise

b $\chi^{2}$ test statistic.

c $t$ test statistic.

the 3-month follow-up. There was no significant difference in attrition rates in the intervention versus control groups, and attrition did not systematically vary according to demographic or baseline clinical characteristics (data not shown).

Participants were on average 26 years old, primarily of mestizo or mixed race $(n=151[84.8 \%])$, married $(n=70[39.3 \%])$ or in a committed but unmarried relationship ("union libre"; $n=80$ [44.9\%]), and multiparous (mean number of children in addition to the newborn $2.3 \pm 1.2$ ). Additional demographic characteristics are listed in Table 2. The intervention and control groups did not significantly differ in any demographic (Table 2) or obstetric (Table 3) characteristic.

All intervention participants completed the 48 -h post-discharge education session. Only three patients called the nurse to ask for additional advice. In other words, participation in part 2 of the intervention was minimal. The analyses were repeated excluding the three mothers who had contacted the nurse during the 30-day follow-up period, and there were no substantive differences in the results. Therefore, data from these participants were retained in the analyses presented here.

The topics of the mothers' conversations with the nurse during the education session were recorded (Table 4). With regard to infant care, the most common topics were infant feeding, recommended schedule of well-baby visits, environmental safety, and regulating sleep. The most frequent maternal self-care topics of discussion were family planning methods, bleeding, and pain.
Table 4

Content of nurse-patient phone calls $(n=102)$.

\begin{tabular}{ll}
\hline Topic $^{\text {a }}$ & $\begin{array}{l}\text { No. }(\%) \text { of calls in which } \\
\text { topic was queried }\end{array}$ \\
\hline Infant concerns & $36(35.3)$ \\
Feeding & $31(30.4)$ \\
Recommended infant medical visit schedule & $15(14.7)$ \\
Home environment for infant & $13(12.7)$ \\
Sleeping & $12(11.8)$ \\
Warning signs of illness & $10(9.8)$ \\
Urination/defecation & $8(7.8)$ \\
Crying & $7(6.9)$ \\
Umbilical cord care & $6(5.9)$ \\
Vaccinations & $5(4.9)$ \\
Growth and development & $4(3.9)$ \\
Gas & $4(3.9)$ \\
Bathing & \\
Mother concerns & $48(47.1)$ \\
Family planning & $30(29.4)$ \\
Bleeding & $26(25.5)$ \\
Pain & $13(12.7)$ \\
Urination/defecation & $10(9.8)$ \\
Mood & $9(8.8)$ \\
Cleaning vaginal area & $7(6.9)$ \\
Breast care & $6(5.9)$ \\
Maternal nutrition & $5(4.9)$ \\
Cesarean wound care & $2(2.0)$ \\
Postpartum hemorrhage & 6 \\
\hline Mostcals included muttipt & \\
\hline
\end{tabular}

${ }^{a}$ Most calls included multiple topics of discussion regarding both maternal and infant concerns.

The intervention produced significant positive results for both mothers and infants (Table 5). With regard to maternal outcomes, at the 3-month follow-up intervention participants reported higher rates of breastfeeding: 65 (86.7\%) of 75 intervention participants were exclusively breastfeeding as compared with 40 (66.7\%) of 60 control mothers. Accordingly, intervention participants were less reliant on formula: 9 $(12.0 \%)$ in the intervention group were formula feeding as compared with $18(30.0 \%)$ in the control group. Mothers in the intervention group were no more likely than control mothers to be using birth control 3 months post partum. However, intervention participants were more likely to use Implanon (etonogestrel implant) and less likely to use condoms, indicating that the intervention was associated with using a less fallible form of contraception. No effect of the intervention on attendance at maternal postpartum visits was observed.

With regard to infant outcomes, mothers in the intervention group were more likely to take their newborn to the well-baby check-up within 1 week of birth, but were no more likely to attend the recommended 2-month infant check-up. In addition, intervention participants reported that their infants had significantly fewer acute illnesses requiring a clinic visit.

Participants expressed nearly universal satisfaction with the intervention: 101 (99.0\%) mothers agreed with the statement "this program had a positive impact on my infant's health;" 100 (98.0\%) with "I would like to have access to this service at my next birth;" and 102 (100.0\%) with "I would recommend this program to a friend."

\section{Discussion}

The present study found that intervention participants were more likely than control mothers to be exclusively breastfeeding at the 3-month follow-up, which is a good predictor of longer-term sustained breastfeeding $[21,22]$. They were also more likely to attend the newborn well-baby check-up and less likely to require emergency clinic visits for acute infections in their infants, perhaps owing to the protective effect of breastfeeding on infant infection and illness [23]. Currently, $40 \%$ of infant deaths in low-income countries occur in the neonatal period; as a result, reducing acute illnesses in this period is an important step toward reducing child mortality [8]. 
Table 5

Outcomes of intervention on maternal and infant health at 3 months after delivery. ${ }^{\text {a }}$

\begin{tabular}{|c|c|c|c|c|}
\hline Outcome & Intervention $(\mathrm{n}=75)$ & Control $(n=60)$ & Statistic & $P$ value \\
\hline Breastfeeding exclusively at 3 months after delivery & $65(86.7)$ & $40(66.7)$ & $7.93^{\mathrm{b}}$ & 0.005 \\
\hline Feeding formula at 3 months after delivery & $9(12.0)$ & $18(30.0)$ & $6.83^{\mathrm{b}}$ & 0.016 \\
\hline Infant attended newborn check-up & $54(72.0)$ & $32(53.3)$ & $5.25^{\mathrm{b}}$ & 0.022 \\
\hline Infant attended 2-month check-up & $74(98.7)$ & $59(98.3)$ & $0.00^{\mathrm{b}}$ & $>0.999$ \\
\hline Using any contraception at 3 months after delivery & $57(76.0)$ & $41(68.3)$ & $0.03^{\mathrm{b}}$ & 0.871 \\
\hline \multicolumn{5}{|l|}{ Contraception type used } \\
\hline Birth control pill & $22(38.6)$ & $18(43.9)$ & $0.67^{\mathrm{b}}$ & 0.412 \\
\hline Tubal ligation & $18(31.6)$ & $13(31.7)$ & $0.07^{\mathrm{b}}$ & 0.793 \\
\hline Implanon & $13(22.8)$ & $2(4.9)$ & $5.19^{\mathrm{b}}$ & 0.023 \\
\hline Injection & $5(8.8)$ & $4(9.8)$ & $0.08^{\mathrm{b}}$ & 0.776 \\
\hline Condoms & $2(3.5)$ & $6(14.6)$ & $14.42^{\mathrm{b}}$ & 0.036 \\
\hline Intrauterine device & $3(5.3)$ & 0 & $2.06^{\mathrm{b}}$ & 0.151 \\
\hline Acute episodes requiring clinic visit: mother & $1.37 \pm 0.81$ & $1.31 \pm 0.68$ & $0.49^{\mathrm{c}}$ & 0.624 \\
\hline Acute episodes requiring clinic visit: infant & $3.66 \pm 1.17$ & $4.19 \pm 1.14$ & $-2.62^{\mathrm{c}}$ & 0.010 \\
\hline
\end{tabular}

${ }^{a}$ Values are given as number (percentage) or mean \pm SD, unless indicated otherwise.

b $\chi^{2}$ test statistic.

c $t$ test statistic.

Influencing a mother's use of birth control and attendance at the postpartum visit may require additional attention or alternative strategies. Overall, $45 \%$ of intervention participants requested additional information regarding family planning methods during their educational conversation with the nurse; however, only $28 \%$ reported using contraception at 3 months, a proportion that was not significantly different from the control group. This may indicate limited access to contraception despite an interest in using it. However, intervention participants reported using more effective methods as compared with the control group, perhaps indicating positive effects of the nurse's education on the relative efficacy of various forms of contraception among those who achieved access.

Another area in which the intervention had limited impact was in infants' attendance at the 2-month well-baby visit: both the intervention and control groups had $100 \%$ attendance at this visit. Because vaccines are routinely performed at this visit, mothers have a strong incentive to attend. However, the 2-month well-baby visit is too late to attend to critical topics such as challenges with breastfeeding and acute illnesses. Earlier interventions, such as the current telephone-based program, are needed to support healthy behaviors from day one.

Ease of use and scalability are significant challenges to developing universal prevention programs in low-resource settings [17]. The current intervention is notably less intensive and less costly than other programs aimed at improving breastfeeding in low-resource countries, which include multiple weekly or biweekly educational sessions and hospital-based instruction [14,15]. In the current intervention, one 30-min telephone session resulted in significant differences in exclusive breastfeeding at 3 months post partum (90\% vs $68 \%$ in intervention vs control groups). Aside from breastfeeding, the most frequent topics of mothers' concerns (family planning, infant check-ups, and maternal postpartum self-care) are also amenable to telephone intervention for triaging further actions.

With regard to scalability, the intervention was delivered by local Ecuadorian nurses who followed their usual parameters for evaluation and follow-up of patients. No additional substantive training was necessary to equip the nurses to deliver the intervention. The intervention also addresses a self-identified high-priority need: it was conceived, designed, and implemented in collaboration with Ecuadorian colleagues who identified a need for improved postpartum follow-up care. Postpartum patient education is one of five strategies identified in the country's National Plan to Reduce Maternal and Infant Mortality [7]. Telemedicine and mobile health platforms are gaining popularity in Ecuador, although they are primarily used to deliver specialty care to remote areas of the country [24]. Integrating mobile phones in postpartum care is an innovative strategy to improve postpartum care by harnessing the current momentum for telephone-based medicine and the high use of mobile devices in the country.
The study has some limitations: the sample size was relatively small, although it was large enough to adequately power the design; there was some attrition over the 3-month follow-up period, although it was not systematic; and the measures at follow-up were selfreported. In addition, the program was tested in an urban setting and its generalizability to non-urban settings is unknown. Lastly, a follow-up of longer than 3 months may be required to fully capture some postpartum behaviors, particularly initiation of contraception and sustained exclusive breastfeeding.

The immediate postnatal period is fraught with challenges for newborn and maternal health. The mobile phone-based postpartum intervention was found to be an effective method of delivering follow-up care in the community. The program's positive effects on health, compatibility with national priorities and available resources, and acceptability to mothers make it a strong candidate for large-scale implementation to improve infant health from day one.

\section{Acknowledgments}

The research was supported by a pilot grant from the University of Michigan Center for Global Health. J.M. is a Faculty Research Associate and C.E.H. is a graduate student trainee of the Population Research Center at the University of Texas at Austin, which is supported by the Eunice Kennedy Shriver National Institute of Child Health and Human Development (R24HD042849 and T32HD007081). S.D.M. was supported in part by grants from the Breast Cancer Research Foundation and the National Cancer Institute (P30CA46592).

\section{Conflict of interest}

The authors have no conflicts of interest.

\section{References}

[1] World Health Organization. Trends in Maternal Mortality: 1990 to 2013. Estimates by WHO, UNICEF. UNFPA, The World Bank and the United Nations Population Division. http://apps.who.int/iris/bitstream/10665/112682/2/9789241507226_eng. pdf?ua =1. Published 2014. Accessed December 15, 2014

[2] United Nations. The Millennium Development Goals Report 2014. http://www.un. org/millenniumgoals/2014\%20MDG\%20report/MDG\%202014\%20English\%20web. pdf. Published 2014. Accessed December 15, 2014.

[3] Ekman B, Pathmanathan I, Liljestrand J. Integrating health interventions for women, newborn babies, and children: a framework for action. Lancet 2008;372(9642): $990-1000$

[4] Centro de Estudios de Población y Desarrollo Social (CEPAR). Ecuador-Demographic and Maternal and Child Health 2004 [in Spanish]. http://microdata.worldbank.org/ index.php/catalog/979. Published 2005. Accessed December 15, 2014.

[5] Chiriboga SR. Incremental health system reform policy: Ecuador's law for the provision of free maternity and child care. J Ambul Care Manage 2009;32(2):80-90. 
[6] Adam T, Lim SS, Mehta S, Bhutta ZA, Fogstad H, Mathai M, et al. Cost effectiveness analysis of strategies for maternal and neonatal health in developing countries. BMJ 2005;331(7525):1107.

[7] Ministerio de Salud Publica del Ecuador. National Plan for Accelerated Reduction of Maternal and Neonatal Mortality [in Spanish]. https://aplicaciones.msp.gob.ec/ salud/archivosdigitales/documentosDirecciones/dnn/archivos/PLAN\%20NACIONAL\% 20DE\%20REDUCCI\%C3\%93N\%20ACELERADA\%20DE\%20LA\%20MORTALIDAD\% 20MATERNA.pdf. Published 2008. Accessed July 10, 2015.

[8] Kahn JG, Yang JS, Kahn JS. 'Mobile' health needs and opportunities in developing countries. Health Aff (Millwood) 2010;29(2):252-8.

[9] Agarwal S, Labrique A. Newborn health on the line: the potential mHealth applications. JAMA 2014;312(3):229-30.

[10] Noordam AC, Kuepper BM, Stekelenburg J, Milen A. Improvement of maternal health services through the use of mobile phones. Trop Med Int Health 2011;16(5):622-6.

[11] Evans WD, Wallace Bihm J, Szekely D, Nielsen P, Murray E, Abroms L, et al. Initial outcomes from a 4-week follow-up study of the Text4baby program in the military women's population: randomized controlled trial. J Med Internet Res 2014;16(5), e131.

[12] Lavender T, Richens Y, Milan SJ, Smyth R, Dowswell T. Telephone support for women during pregnancy and the first six weeks postpartum. Cochrane Database Syst Rev 2013;7, CD009338.

[13] Baker-Ericzén MJ, Connelly CD, Hazen AL, Dueñas C, Landsverk JA, Horwitz SM. A collaborative care telemedicine intervention to overcome treatment barriers for Latina women with depression during the perinatal period. Fam Syst Health 2012; 30(3):224-40.

[14] Tahir NM, Al-Sadat N. Does telephone lactation counselling improve breastfeeding practices? A randomised controlled trial. Int J Nurs Stud 2013;50(1):16-25.
[15] Fu IC, Fong DY, Heys M, Lee IL, Sham A, Tarrant M. Professional breastfeeding support for first-time mothers: a multicentre cluster randomised controlled trial. BJOG 2014;121(13):1673-83.

[16] Lund S, Rasch V, Hemed M, Boas IM, Said A, Said K, et al. Mobile phone intervention reduces perinatal mortality in Zanzibar: secondary outcomes of a cluster randomized controlled trial. JMIR Mhealth Uhealth 2014;2(1), e15.

[17] Tamrat T, Kachnowski S. Special delivery: an analysis of mHealth in maternal and newborn health programs and their outcomes around the world. Matern Child Health J 2012;16(5):1092-101.

[18] Maslowsky J, Valsangkar B, Chung J, Rasanathan J, Cruz FT, Ochoa M, et al. Engaging patients via mobile phone technology to assist follow-up after hospitalization in Quito, Ecuador. Telemed J E Health 2012;18(4):277-83.

[19] The World Bank. Ecuador. http://data.worldbank.org/country/ecuador. Published 2015. Accessed January 16, 2015.

[20] International Telecommunication Union. Time series by country: Mobile cellular subscriptions. http://www.itu.int/en/ITU-D/Statistics/Pages/stat/default.aspx. Published 2015. Accessed October 22, 2015.

[21] Kronborg H, Vaeth M. The influence of psychosocial factors on the duration of breastfeeding. Scand J Public Health 2004;32(3):210-6.

[22] Semenic S, Loiselle C, Gottlieb L. Predictors of the duration of exclusive breastfeeding among first-time mothers. Res Nurs Health 2008;31(5):428-41.

[23] Oddy WH. Breastfeeding protects against illness and infection in infants and children: a review of the evidence. Breastfeed Rev 2001;9(2):11-8.

[24] Lopez-Pulles R, Vilela L, Fernández G. National telemedicine Program/TelehealthEcuador [in Spanish]. Lat Am J Telehealth 2010;2(3):286-301. 